\title{
Artikel
}

Katja Kanzler*

\section{Invective Form in Popular Media Culture: Genre - Mode - Affordance}


Abstract: The following article outlines a way to conceptualize invective form in popular culture that is particularly interested in accommodating the range, fluidity, and slipperiness that define pop-cultural invectivity. It is an approach that draws on one very well-established concept of formal criticism - that of mode - and one concept that has recently been brought to the fold of formalist inquiry - that of affordance. I will argue that conceiving of invective form in popular culture as a mode and as an affordance allows to address the diversity and range of external forms by which pop-cultural invectivity operates. In addition, it brings into focus the fluidity that marks the repertoire of invective popular culture, its paradoxical tendency to gravitate toward routinization in more set conventions, only to conspicuously push against these conventions' boundaries. Finally, to conceive of the invective valence of the mode's repertoire not as a fixed property but as an affordance helps talk about the volatility and dynamism of invective performances in popular culture, the way in which their invective effects are contingent on the social positionality from and for which they realized, and the way in which their invective valence is open for resignification.

Keywords: invective mode; affordance, genre criticism, modal criticism, popular culture, resignification, US-American culture - Affordanz, Genrekritik, Populärkultur, Resignifikation, US-amerikanische Kultur, Invektivität, Modaltheorie

*Prof. Dr. Katja Kanzler, Leipzig University, American Studies, Professor and Chair for American Literature, katja. kanzler@uni-leipzig.de

Throughout the 2010s, HBO's Veep ${ }^{1}$ was one of the reliably successful contenders in television award competitions. Veep stood out as a profanity-ridden comedy, revolving around the character of a foulmouthed female vice president and a satirical portrayal of the political class as narcissistic and incompetent. The show came to an end in 2019, after both producers and commentators had been noting how the arrival of a real president that rivaled the show's fictional one both in incompetence and offensiveness had made it difficult to write for the show. At about the same time, a program that broke viewer records as the most watched cable reality tv show was Duck $D_{\text {Dynasty }}^{2}$, a family reality show that staged its protagonists, the Robertsons, as 'rednecks' - a derogatory stereotype of poor white people in the rural South that the show both actualized in its portrayal of the Robertsons as spectacularly crass and unsophisticated, and that it resignified at the same time as a badge of anti-elite pride. One of the protagonists, Willie Robertson, gave a speech

1 Ianucci (2012-2019) Veep.

2 A\&E Networks (2012-2017) Duck Dynasty. at the Republican National Convention that nominated Donald Trump as the party's presidential candidate. Finally, in the wake of Trump's eventual election, The Late Show with Stephen Colbert ${ }^{3}$ saw a phenomenal rise in popularity, turning into the most watched program on the crowded Late Show-market - especially among viewers that represent the kind of urban, liberal 'elites' that the Robertsons regularly belittled. Commentators consistently suggest that it became so successful because of its extensive satiric put-downs of president Trump. ${ }^{4}$

That list could be continued. What it illustrates is that contemporary US-American popular culture is ripe with moments of invective: ${ }^{5}$ Popular media culture of the $21^{\text {st }}$ century, to a significant

3 Colbert (2015-present) Late Show.

4 This is recurrent theme in commentary on how the ratings of Colbert's show have been rising since the beginning of Trump's presidency. For a recent example, see Koblin's article (2019) in The New York Times.

5 It might seem tempting to trace the invective orientation of contemporary US popular culture to Donald Trump's presidency. However, I would suggest that Trump's ascendancy to the White House is not cause of the apparent invective turn in the popular but another symptom. After 
extent, organizes around performances of depreciation, devaluation, disparagement; or, the other way around, performances of invective unfold considerable popular appeal in the commercial media culture of the contemporary moment. The above examples further illustrate that these invective performances are marked by a notable diversity: They are diverse in terms of the flavors of symbolic abuse that they dramatize, ranging from (seemingly playful) ridicule and mockery to (seemingly serious) insult and vituperation. They are also diverse in terms of how they actualize the antagonistic constellation of invective practices, ${ }^{6}$ from scenarios of intradiegetic confrontation in which invector and invectee are present in and as characters, to constellations of invective by proxy in which the devaluation originates from the authorial agency of the 'text', manifesting itself in patterns of characterization that invectively construct characters as other, debased, inferior. ${ }^{7}$

As a scholar working in the tradition of American studies, I am chiefly interested in the cultural work that these invective moments do, and I believe that, to fully understand this work, we need to look at their form(s): The forms of popular culture organize what its materials can say and do; they 'order, pattern, and shape' the ways in which these materials can "help[...] construct the frameworks, fashion the metaphors, create the very language by which people comprehend their experiences and think about their world." 8 But how is it possible to conceptualize the formal principles of pop-cultural invectivity in the face of such diversity? The arguable master category of formal criticism, genre, is very productive for exploring the conventions of specific formations of this invectivity - say, of particular, historically

all, Trump's public persona, which he still capitalizes on, was made on television.

6 In talking about constellations of invective practice, I am taking my cue from Ellerbrock/Koch/Müller-Mall et al. (2017) Invektivität. The article serves as a major intellectual framework for my thinking throughout this essay.

7 For a more detailed discussion of the distinction between authorial and figural invective in narrative materials, see Kanzler (2019) (Meta)Disparagement, p. $16 f$.

8 Lauter (1999) Reconfiguring, p. 23. This is Paul Lauter's influential definition of cultural work. The phrase 'order, pattern, and shape' is adapted from Caroline Levine's conception of form in her influential book Forms: Whole, Rhythm, Hierarchy, Network, which has greatly inspired my overall thinking in this essay. and medially specific formations of comedy that producers and consumers treat as genres ${ }^{9}$ - but it runs into its limitations when one is interested in the larger phenomenon. My thinking in this essay proceeds from the observation that pop-cultural invectivity regularly exceeds the boundaries of genre(s). There seem to be multiple reasons for this. One is that symbolic abuse in popular culture draws on such a wide range of rhetorical tools and emotional registers, from insult to mockery, from rage to condescension, from the fictionalized or playful to the sincerely vitriolic and, frequently, pop-cultural materials keep the boundaries between these poles conspicuously blurry. As pop-cultural invectivity thus spans not individual but a multiplicity of genres, where it is more or less pronounced, conceptualizing it solely in terms of genre would result in a list of genres that always feels incomplete.

A second reason is that the popular forms of symbolic abuse seem to oscillate between poles of fixity and fluidity: On the one hand, they are often tied to tried-and-true conventions, to formulas and stereotypes that have proven to put down, to provoke. But on the other hand, they are constantly adapting to new medial and social ecosystems, within a market framework that encourages some degree of distinction, e.g. through the strategies of "serial outbidding" that Kelleter/ Jahn-Sudmann theorize. ${ }^{10}$ Invective popular culture seems to intensify the "dialectic of repetition and innovation" that Eco observes in popular culture in general: ${ }^{11}$ Invectivity is uniquely suited for the conspicuous breaking of conventions, for pushing the boundaries of what is usually seen and heard on popular media, for moments of provocation. At the same time, invectivity in popular culture seems to require routinization and ritual, possibly to defang and reign it in, possibly also in order to accrue cultural meaning.

A third and final reason might be that - because invectivity in popular culture is not primarily

9 As Jane Feuer (1992) highlights, television-, and more broadly, popular media-studies tends to work with a concept of genre as a "tacit contract between the motion picture industry and the audience" (p. 143), as "systems of orientations, expectations, and conventions that circulate between industry, texts, and subjects" (p. 144), as she puts it with Steve Neale.

10 Kelleter/Jahn-Sudmann (2012) Dynamik.

11 Eco (1997) Innovation and Repetition, p. 26. 
designed to hurt and put down people, but to sell entertainment - it is notoriously slippery in its rhetorical motivations and meanings. As the economic logic of commercial popular culture demands that its materials reach the largest possible audience, ${ }^{12}$ one might even argue that its materials are actively interested in not offending anyone. So invective popular culture tends to ambiguate its intentions and meanings, playing with the boundaries between actual and non-actual communication (e.g., fiction/non-fiction, irony/sincerity), and often encouraging practices of appropriation that resignify insult as empowerment.

In the following, I want to outline a way to conceptualize invective form in popular culture that is particularly interested in accommodating the range, fluidity, and slipperiness that define pop-cultural invectivity. It is an approach that draws on one very well-established concept of formal criticism - that of mode - and one concept that has recently been brought to the fold of formalist inquiry - that of affordance. My underlying argument is that conceiving of popular invective as a mode and as an affordance brings into focus aspects that are quite central to the phenomenon yet hard to grasp with other formalist approaches. I will illustrate my theoretical reflections with a few examples from the tv show Duck Dynasty that I just mentioned.

\section{Mode: Invective as (Performative) Practice}

For quite some time now, the concept of mode has been a go-to fix for moments when formal criticism runs into the limitations of genre. It is particularly in moments where scholars aim to theorize forms across historical periods or media that the concept of genre often becomes too rigid. This is the case, for example, when Griffin seeks to conceptualize satire across the centu-

12 The economic organization of commercial popular culture has, of course, changed considerably with the advent of new media and the attendant shift from an economy of broadcasting to one of 'narrowcasting' and niche marketing. In this new economy, it can make sense to offend and lose some audiences in order to win and bind other, economically more interesting audiences. But even in such niche constellations, audience size does matter. ries of its use. ${ }^{13}$ No generic category, he finds, can accommodate "satire's immense and perhaps incomprehensible variety: (in verse alone) formal satire, epistle, letter from the country, lampoon, epigram, session of the poets, advice to a painter - to say nothing of parodic forms." ${ }^{\prime 14}$ Along with several other scholars, ${ }^{15}$ he instead proposes to think of satire as a mode or "procedure" that can tie itself to all kinds of formal expressions.

Yet not only a form like satire, that shares the diversity and dynamism of invective, poses such problems, also a seemingly more narrow and specific literary form like the picaresque does. When Wicks theorizes the picaresque as it manifests itself from 17th-century Spanish narratives to the 20th-century novel, he also finds that the concept of genre does not work:

The search for a picaresque genre concept has fluctuated between two extremes, which ultimately cancel themselves out: a rigidly historical approach that seeks a genre so pure that no two texts together can verify it, and an ahistorical approach that posits a genre concept so inclusive that its many texts in their diversity invalidate it. ${ }^{16}$

His solution, too, is to conceptualize the picaresque as a mode which features "in widely varying degrees in much fiction that could not by even the most generous generic measure be considered picaresque fictions proper."17

In their details, the modal concepts that Griffin and Wicks use are not fully congruous - in fact, it often seems that mode can operate as a solution to problems of genre criticism precisely because it is a somewhat suggestive category, capable of mobilizing thinking thanks to a productive openness ${ }^{18}$. What does unite Griffin's and Wicks' uses of mode, however, is that they approach it as a

13 See especially Münkler in this issue.

14 Griffin (1994) Satire, p. 3.

15 See, e.g., Fowler (1982) Kinds; Knight (2004) Literature; Phiddian (2013) Satire.

16 Wicks (1989) Picaresque, p. $36 f$.

17 Wicks (1989) Picaresque, p. 43.

18 Because the term 'mode' is so suggestively open, it has been employed and theorized in several contexts. Next to its development in the context of genre criticism, with which I am concerned here, one notable other example would be the concept of 'narrative modes' that is used in narratology. 
category that is independent of form in the narrow sense - as, if you will, a practice rather than a form. Wicks thinks of modes as distinct ways of imagining fictional worlds - of imagining them as "better than the world of experience, [...] worse than it, or [...] more or less equal to it"; 19 for Griffin, modes denote even more loosely conceived 'procedures' of fiction. Across its often incongruous uses, the term mode denotes specific practices of creating textual artifacts: ways of writing ${ }^{20}$ or performing aesthetically mediated communication, which can be realized in a potentially openended variety of formal ways. This conception of mode as a practice has two consequences that are particularly significant for my purposes. One is gradability: Modes do not have to be thought of in terms of absolute presence or absence; they can be present in textual artifacts to a gradable extent, i.e., more or less prominently. The second consequence follows from this: Textual artifacts are regularly informed by more than one mode. Modes regularly cohabit and interact with each other in textual artifacts.

Thus approaching mode as a practice makes it a very open, perhaps unproductively vague concept. To get a better fix on its conceptual boundaries, several scholars have considered a relationship between modes and genres. Fowler, who has developed one of the most comprehensive theorizations of literary types in Anglo-American studies, argues that modes are closely related to genres, or "kinds", as he calls them. For him, kinds are historically situated genres that distinguish themselves by particular properties - a "generic repertoire" 21 - which usually includes a broad range of aspects: distinctive subjects, character types, plot-structures, topoi, moods, styles, values, and, importantly, always a distinctive external form. Some of these kinds, he observes, become transformed into modes. And while Fowler concedes that we simply might not yet have recognized all the modes that are circulating in the culture, ${ }^{22}$ his examples suggest that it tends to be the culturally most resonant

19 Wicks (1989) Picaresque, p. 41.

20 The phrase 'ways of writing' indicates that there is significant overlap between the modal theory I outline and German-language theorizing on 'Schreibweisen' (see especially Hempfer [1973]).

21 Fowler (1982) Kinds, p. 55.

22 Fowler (1982) Kinds, p. 109. and productive kinds that 'bleed' into modes. In modes, the generic properties of kinds become translated into more generalized, more flexible and mobile, less formally bound principles. Compared to kinds, modes feature a reduced generic repertoire, "a selection only of the corresponding kind's features, and one from which overall external structure is absent." ${ }^{\prime 23}$ The fact that modal terms tend to be adjectives (satiric, comedic) while the terms for genres are nouns (satire, comedy), for Fowler, highlights that "modal terms never imply an external form." ${ }^{24}$ One of the key effects of a kind's transformation into a mode is mobilization: Its generic repertoire gets mobilized both synchronically, across different external forms, and diachronically, across time.

If one follows Fowler's ideas to think the invective in popular culture as a mode, this immediately raises the question what might be the parent genre of such an invective mode. This is a challenging question - and its challenges, in fact, echo the problems that Fowler himself has when identifying a singular generic 'source' for some of the modes he discusses. ${ }^{25}$ Perhaps the process of exchange between genres and modes it not as unidirectional as Fowler wants to have it, but rather goes both ways: Genres can become mobilized as modes, and just as regularly, modes coagulate into genres, i.e., they attach themselves to external forms that become conventionalized as historically situated kinds. The question what came first, the genre or the mode, might be less significant than acknowledging a dialectical relationship between the two.

Reconceiving Fowler's ideas in this way slightly shifts the question, to the effect of asking what might have been early genre formations in which the invective mode took solid shape and evolved its modal repertoire. I want to point to two particularly influential formations within English-language traditions - which, incidentally, overlap to an extent that seems to stand testimony to the existence of a connecting, possibly prior, modal

23 Fowler (1982) Kinds, p. 107.

24 Fowler (1982) Kinds, p. 107.

25 For Fowler (1982) Kinds, the most challenging mode is, again, the satiric: "Satire is the most problematic mode to the taxonomist, since it appears never to have corresponded to any one kind", he writes, and ends up concluding: "Diversity of form is paradoxically the 'fixed' form of satire" (p. 110). 
impulse. One is a form known as 'flyting,' a practice of stylized invective contest that circulated across some of the earliest canonical English texts, including Chaucer's Canterbury Tales and several of Shakespeare's plays, and that became tightly conventionalized in 15th- and 16th-century Scottish poetry. ${ }^{26}$ These flyting poems - like the other literary uses, related to even older conventions of flyting in heroic epic traditions - were highly patterned confrontations between two poets, in which each tried to demonstrate his superior poetic skill through ever more elaborate and fanciful insults of the other. While performances of flyting in the epic tradition characteristically involve warrior-characters who follow up their verbal confrontation with physical battle, Parks notes, Scottish flyting poetry constitutes what he calls "ludic flyting" which "does not seem to bring with it any martial entailments." ${ }^{27}$ In flyting poetry, poets take out their rivalry on the field of a purely verbal, invective contest. While the rivalry between them might have been real and might have formed an actual motivation for the attack, its performance in poetry was framed as entertainment. ${ }^{28}$ The genre's conventionalized strategies for demonstrating superiority include the use of technically demanding stanzaic forms, creative realizations of the established topoi of insult (non-normative physical appearance, sexual practices, family origin, poetical [in]eptitude, etc.), the use of a conspicuously sophisticated lexicon but also of conspicuously vulgar words. ${ }^{29}$ Flyting poetry - with its many ties in foundational Anglophone literary traditions and its many echoes in contemporary popular culture - could be argued to be one early genre formation in which the invective mode attached itself to a set of cul-

26 See, e.g., Hendricks (2012) Battle, especially pp. 71-74 and p. $90 f$.

27 Parks (1986) Flyting, p. 441.

28 As Hendricks (2012) Battle, p. 73, points out, "[l]ate medieval Scottish flytings were typically performed at court and have usually been discussed as light-hearted albeit vulgar - roasts appropriate for an intimate group of courtiers".

29 These conventions are identified in Flynn and Mitchell's analysis of two of the most well-known examples of flyting poetry, The Flyting of Dunbar and Kennedie (ca. 14901505) and Invectuies Captain Allexander Montgomeree and Pollvart (ca. 1580-83) (Flynn/Mitchell [2014] Interpreting). turally recognized conventions and evolved its modal repertoire.

The other genre I want to point out is satire, with its robust and lively tradition in the English-language imagination, which also informs so much of contemporary popular culture. Of course, it would be more accurate to speak of several generic formations here, since the satiric, as already noted, has tied itself to several external forms, also in the foundational periods of Anglophone literary history, ranging, if you will, from John Dryden's poetry to Jonathan Swift's prose. Satire is one of the literary formations that Northrop Frye discusses in his seminal Anatomy of Criticism, and interestingly, he delineates it by talking about its boundaries to neighboring formations, including that of flyting (which he treats as synonymous with 'invective'). He points to two properties that supposedly distinguish satire, and his phrasing indicates that they mark highly porous boundaries. One is the moral motivation that ostensibly drives invective attacks in satire the conviction that the people, human behaviors, or social formations that are disparaged are wrong, and that attacking them serves a greater good. Frye aptly depicts this as a claim that satiric materials make, a textual performance that might be as fictional as other moments in the materials, ${ }^{30}$ but a property that distinguishes the generic repertoires of satire. The other property he identifies is the use of humor and irony. He describes flyting as "satire in which there is relatively little irony"; 31 and he adds: "Attack without humor, or pure denunciation, forms one of the boundaries of satire", ${ }^{32}$ admitting: "[i]t is a very hazy boundary." ${ }^{\prime \prime 3}$ Frye sees the reason for this haziness in the popular appeal of invective - "[i]t is an established datum of literature that we like hearing people cursed and are bored with hearing them

30 Frye himself uses the satiric technique of mockery to make this point, singling out the English writer Alexander Pope as his target: "The satirist commonly takes the high moral line. Pope asserts that he is 'To Virtue only and her friends a friend,' suggesting this is what he is really being when he is reflecting on the cleanliness of the underwear worn by a lady who had jilted him" (Frye [1957] Anatomy, p. 225).

31 Frye (1957) Anatomy, p. 223.

32 Frye (1957) Anatomy, p. 224.

33 Frye (1957) Anatomy, p. 224. 
praised"34 - which makes it tempting for writers to falsely claim moral motivations in order to legitimize their invective writing. One might add that the boundary is also hazy because humor is not entirely absent from flyting, either, but rather forms an important part of its generic repertoire.

So I suggest that, in English-language imaginary traditions, flyting and forms of satire are two early and influential genre formations in which the invective mode evolved its modal repertoire. This repertoire revolves around a poetics of devaluation, negotiating a hierarchy between a speaker (speaking directly or indirectly, through figural or authorial voices) and an addressee (addressed directly or by proxy). The repertoire can suture the audience into the textual world in different places, often - through not always - working to make them side with the invective agency. This is a highly volatile operation, whose volatility a purely modal concept cannot fully explain. I will come back to this. When it comes to formal techniques, the repertoire of the invective mode is very broad and constantly evolving. This breadth and dynamism is tied to the diversity of formal techniques in the genre formations in which the invective mode has developed its repertoire. It is additionally tied to the premium that these genres have placed on inventiveness and creativity in invective expression. Finally, I would note that the invective mode regularly cohabits with other modes, especially when it is realized in (larger) narrative forms: Narrative, thanks to the requirements of emplotment, rarely can do with a poetics of devaluation alone.

Let me take a moment to illustrate this with the example of Duck Dynasty. The show is shaped by the conventions of a reality tv-subgenre typically called family reality shows: depictions of a family's everyday life that claim to be factual (though they are, of course, highly stylized and formulaic). Most family reality shows focus on celebrities, with the dual promise of offering tabloid-like insights into the private lives of media stars, and of disclosing the eccentricities, if not pathologies, that lie hidden underneath the glamor. ${ }^{35}$ Duck

34 Frye (1957) Anatomy, p. 224.

35 E.g. The Osbournes (2002-2005), Newlyweds: Nick and Jessica (2003-2005), Run's House (2005-2009), and, of course, Keeping up with the Kardashians (2007-present). See Andrejvic (2004) Reality TV, pp. 10-12.
Dynasty slightly varies these conventions in that its protagonists are not prior media celebrities, but a Louisiana-based family staged as 'regular', the Robertsons, who became rich within one generation with a business that markets paraphernalia for duck hunting. It would hardly be convincing to call the family reality show an invective genre, yet it clearly features invective moments that it shares with other formats of (popular) culture. It is, in other words, informed by an invective mode.

In Duck Dynasty - as in other shows of this genre - the invective mode manifests itself, for one, in how the protagonists are portrayed. The poetics of devaluation that animate this portrayal particularly surface in how the show takes recourse to an established derogatory stereotype - that of the 'redneck'. 'Redneck' is an (originally) disparaging epithet for poor white people from the rural South, figuring them as "God-fearing, gun-toting, truck-driving, inbred bumpkin[s],"36 as Marshall polemically summarizes the stereotype's contemporary semantics. The show's recourse to this stereotype becomes visible in its visual staging of the (male) Robertsons' non-optimized bodies, with long, seemingly unkempt hair and beards, and usually clad in camouflage; in extensively dramatizing their love for hunting and fishing; in staging them as loud and crass. As other pop-cultural artifacts that are informed by the invective mode, the show hyperbolizes and spectacularizes its protagonists' deviance from contemporary norms (normative body practices, norms of gentility, etc.) in ways that recall the 19th-century format of the freak show. ${ }^{37}$ One recurrent motif in the Robertsons' staging as crass is an open disdain for the kind of urban, bourgeois identity against which the stereotype measures the 'redneck's' alleged inferiority and pathology: The Robertsons, and especially family senior Phil Robertson, regularly bad-mouth people whom they call 'yuppies', but they also use this designation to playfully insult each other. So

36 As Huber (1995) outlines, the stereotype of the 'redneck' has been refigured several times throughout the history of its use. Especially in recent years, it has been used for the valorization of (Southern) whiteness.

37 Several scholars have made comparisons between contemporary reality tv and the 19th-century format of the freak show. See, e.g., Dovey (2000) Freakshow. For a conceptual discussion of invective as spectacle, see Kanzler (2019) Veep, p. $149 f$. 
in addition to the authorial invective of the protagonists' enfreakment, there are performances of figural invective that are equally woven into the fabric of the format's conventions.

Finally, the show clearly does not rely on an invective mode alone. One other modal touchstone I want to mention is the sentimental mode, on which the show especially draws in its staging of the Robertsons' 'family values' - in how it glorifies the Robertson family as an ideal space of mutual affection and functioning sociability. ${ }^{38}$ The show does this, e.g., by regularly staging the bonds of affection that tie the Robertsons together, which among the male main characters sometimes express themselves through playful practices of invective. Yet it especially does this in the formulaic ending that the format features in its episodes: It is an ending that sees the family gathered at the dinner table, with patriarch Phil leading a prayer of grace and his son Willie, in voice over, commenting on how the episode's little crises and conflicts have been resolved. This formulaic final scene - which emphasizes the patriarchal, Christian, tradition-oriented nature of the family - works as a move of narrative closure that affirms the Robertsons' familial cohesiveness and happiness. As such, it also signifies back to the episode's invective moments, giving them a narrative frame that is invested in an ethos quite different from that of invectivity, one of affectively charged expressions of mutual connectivity. So the show's use of the sentimental mode has an impact on how it operates the invective mode (and the other way around): Its sentimentally charged narrative of the Robertsons' love for each other and of their family as an idealized space frames any moments of invective as embedded performances, demanding them to be read against the horizon of this frame narrative. The frame reinforces, e.g., which performances of invective

38 Dobson (1997) influentially defined the sentimental as an "emotional and philosophical ethos that celebrates human connection, both personal and communal" (p. 266), adding: "[s]entimentalism envisions the self-in-relation; family [...], intimacy, community, and social responsibility are its primary relational modes" (p. 267). And I am consciously using the phrase 'family values' here to designate the set of ideas, invoked especially in conservative U.S. politics, that "the nuclear family, with a married heterosexual couple and their children, is the foundation of a solid and healthy democracy" (May [2003] Family Values, p. 7). are connoted as actual and which as instances of non-actual speech (family members playfully insulting each other, for instance, are thus additionally marked as expressions of affection). The sentimental frame also orients the implied audience in its affective response to the Robertsons, encouraging a sense of closeness - the audience being invited to feel with and for the Robertsons which complicates the show's use of a derogatory stereotype in its portrayal of the family. Thus, the invective mode's realizations in this piece of popular culture are greatly shaped by the other modal impulses that suffuse the material.

\section{Affordance: Invective and/as Latent Potential}

As outlined so far, a modal approach can be useful for conceptualizing the invective moments in a format like Duck Dynasty, and for placing the show and its genre within larger contexts of invectively flavored popular culture. But there are aspects of Duck Dynasty's invectivity that the modal approach cannot account for. Most notably, it cannot account for the volatility and dynamism of the show's invective operations. For one, the show's use of the 'redneck' stereotype has triggered amply documented readings as empowering those it allegedly belittles. ${ }^{39}$ Such reading practices could be theorized as resignification - as the performative recoding of "injurious speech acts." 40 But is there a way to talk about how such reception practices are organized by the formal operations of the material itself? In addition, Duck Dynasty is surrounded by numerous paratexts that treat its invective valences not as a given, but as an object of negotiation or conflict. For example, in an interview with the magazine $G Q$, Phil Robertson presented a narrative of his experience of growing

39 Duck Dynasty's substantial fan following bears testimony to such reading practices, as does the extensive merchandise that is marketed for the show.

40 This is Judith Butler's phrase in Excitable Speech (1997), where, building on her thinking about performativity and repetition, she writes: "The interval between instances of utterance not only makes the repetition and resignification of the utterance possible, but shows how words might, through time, become disjoined from their power to injure and recontextualized in more affirmative modes" (p. 15). 
up in the pre Civil Rights-South that invectively dismisses the existence of racism and replicates minstrel stereotypes of Blackness:

Where we lived was all farmers. The blacks worked for the farmers. I hoed cotton with them. I'm with the blacks, because we're white trash. We're going across the field ... They're singing and happy. I never heard one of them, one black person, say, I tell you what: These doggone white people-not a word! ... Pre-entitlement, pre-welfare, you say: Were they happy? They were godly; they were happy..${ }^{41}$

The interview provoked responses that were highly confrontational in themselves: While some commentators maintained that the interview makes explicit a white supremacist stance that is implicit in the show itself, others validated it as an accurate depiction of life in the South, charging the other camp of commentators with offending white Southerners like Robertson by trying to silence them. So, apparently, devaluation is not a fixed and stable property of Duck Dynasty's various textual moves, but a quality that is subject of intense negotiation. Is there a way to integrate this into a model of invective form?

I want to suggest that amending a modal approach to pop-cultural invective with the concept of affordance can help address these questions. Levine adapted the term 'affordance' from design theory in order to reconceive (not only, but also) literary form. In design theory, she notes, "[a]ffordance is a term used to describe potential uses and actions latent in materials and designs." 42 The design parameters of, say, a chair - the materials that are used (wood, plastics, etc.), the shapes into which these are moulded prefigure its use for sitting down. This potential use is programmed into the design of the chair, but still a chair affords more actions than just sitting down: it can be used for standing on it, for putting one's feet up when lying on the floor, etc; and these uses, too, are configured by the chair's design. While "[d]esigned things may ... have unexpected affordances generated by imaginative users," Levine observes, "[e]ach shape or pattern ... lays claim to a limited range of potentialities." ${ }^{\prime \prime 3}$ What is more, the potential uses that are latent in the design of a chair address them-

41 Magary (2013) What the Duck, n.pg.

42 Levine (2015) Forms, p. 6.

43 Levine (2015) Forms, p. 6. selves to particular subjects. An average chair affords sitting down only for an adult human without certain forms of mobility impairment; for other users, it has different affordances. According to design theorist Norman, affordances are therefore not properties of designed things but "relationship[s] between physical objects and people," ${ }^{\prime 44}$ which realize themselves in concrete constellations of use.

Levine now suggests that literary - or, more broadly, communicative - forms ${ }^{45}$ can be thought in analogy to the shapes, patterns, and textures of material design; that they, too, can be approached in terms of their affordances. Doing so means to ask what aesthetic forms are "capable of doing"46, "what potentialities lie latent - though not always obvious - in aesthetic ... arrangements." ${ }^{147}$ Levine's appropriation of the concept of affordance for formalist critique notably moves beyond its more established adaptation in media studies, where it has been used to theorize the potential uses prefigured by particular media technologies and materialities. ${ }^{48}$ Levine turns her attention to the less physical shapes, patterns, and textures of various forms - including the kind of aesthetic forms and means that concern me here - arguing that they, too, carry affordances. ${ }^{49}$

A promising point where this formalist notion of affordance could be brought into conversation with the concept of an invective mode is the idea of a modal repertoire - i.e., of the open-

44 Norman (2002) Design, p. 11.

45 Actually, Levine (2015) Forms, is interested in a much more broadly conceived notion of form that encompasses any "arrangement of elements - [any] ordering, patterning, or shaping" (p. 3), be it aesthetic or social.

46 Levine (2015) Forms, p. 6. Emphasis in the original.

47 Levine (2015) Forms, p. $6 f$.

48 In media studies, the term affordance has especially been employed to discuss the potential uses programmed into new media. See, e.g., the contributions in Gillespie/ Boczkowski/Foot (2014) Media Technologies. The key point of reference for such uses of the term is often Hutchby (2001) Technologies.

49 This formalist adaptation of the concept has begun to inspire intriguing scholarship; see, e.g., von Contzen's (2017) work on the affordances of lists or Jaussen's (2018) on those of catalogues. While much of this scholarship takes as its point of departure a specific form and asks for its affordances, I proceed the other way around: As I will outline, my point of departure is a particular affordance namely the devaluation and symbolic injury of subjects which I tie to the formal repertoire of the invective mode. 
ended repertoire of forms and means on which the invective mode draws. Taking my cue from Levine, I want to propose that one way to delineate the elements in this modal repertoire would be to say that they afford the devaluation and symbolic injury of subjects. Conceiving of this invective valence as an affordance means to conceptualize it not as a fixed and stable property of elements in the invective mode's repertoire, but as a latent potential that can (or cannot) be realized in its individual uses. At the same time, it means to acknowledge that the elements of this modal repertoire have other affordances, which can be realized in tandem with or alternative to each other. For example, the insignia of the image of the 'redneck' that Duck Dynasty operates can be used to signify shame, but they also afford the expression of pride. For the media commodity that the show is, performances that are drenched in offensive stereotypes afford the accrual of attention. And, to point to another element in the invective's modal repertoire, epithets - like the word 'yuppie' that is framed as an epithet in the show's storyworld - afford the expression of disdain (when directed at subjects outside the protagonists' community, demarcating this community's boundaries in the process), but they also afford playful expressions of affection and intimacy within that community. Even the most conventionalized means of invective communication are not just invective; nor are they invective all the time, nor to everybody.

Conceiving disparagement as an affordance opens up several interesting questions for a new-formalist inquiry into invective popular culture. For one, it directs attention to the kinds of affordances that accumulate in the invective's modal repertoire - convergences like the ones I just exemplified (potentials to express shame pride; injury - attention; disdain - affection). Are such convergences the result of local realizations of the invective mode, or are they systematic phenomena that inhere in (potentially invective) signifiers? Are there expressive affordances that are intrinsically related? And how exactly are the different affordances and their realizations interlaced in the material and in the media practices around it? Do they inform, inflect, or compete with each other? Are there any intersectional effects that can be observed?
In addition, the concept of affordance brings into focus the extent to which invective repertoires address themselves to particular subject positions. In fact, the relationship between invective affordances and the subjects who realize them is so strong that such practices can be argued to performatively bring these subject positions into being. In this sense, affordances configure subject positions. For example, the label 'yuppie' has invective affordances only for subject positions like the ones from which Duck Dynasty's protagonists speak. At the same time, these invective affordances configure the 'plebeian', rural subject position which the Robertsons perform by using the label as an epithet. Similarly, the different affordances of the 'redneck'-stereotype depend on the subject position from which the stereotype's insignia are used. In Duck Dynasty, the position from which these insignia afford the expression of pride is both classed and gendered - the male Robertsons can use them in ways that the female members of the family cannot. The kind of lower-class masculinity that the characters perform by realizing the 'redneck'-stereotype's potential to express pride is, again, configured by this affordance - and it is clearly a performative accomplishment: By economic standards, the Robertsons are, of course, everything but lower class. In what Walton has aptly described as "redneck drag," ${ }^{\prime 50}$ they perform themselves as proud 'rednecks,' stylizing themselves in a subject position that is configured by the expressive affordances of the 'redneck'-stereotype.

To conclude, for an interest in the invective dynamics in and of US popular culture, conceptualizing the invective as a mode and as an affordance opens up several avenues for productive inquiry. It allows to address the diversity and range of external forms by which pop-cultural invectivity operates. In addition, it brings into focus the fluidity that marks the repertoire of invective popular culture, its paradoxical tendency to gravitate toward routinization in more set conventions, only to conspicuously push against these conventions' boundaries. Finally, to conceive of the invective valence of the mode's repertoire not as a fixed property but as an affordance helps talk about the volatility and dynamism of invective performances in popular cul-

50 Qtd. in O'Sullivan (2016) Playing, p. 372. 
ture, the way in which their invective effects are contingent on the social positionality from and for which they realized, and the way in which their invective valence is open for resignification.

\section{Works Cited}

A\&E Networks, developer (2012-2017): Duck Dynasty. New York: A\&E Networks.

Colbert, Stephen, creator (2015-present): The Late Show with Stephen Colbert. New York: CBS Television.

Iannucci, Armando, creator (2012-2019): Veep. New York: HBO.

Andrejevic, Mark (2004): Reality TV: The Work of Being Watched. Lanham: Roman \& Littlefield.

Butler, Judith (1997): Excitable Speech: A Politics of the Performative. New York: Routledge.

Dobson, Joanne (1997): Reclaiming Sentimental Literature. In: American Literature 69/2, pp. 263-288.

Dovey, Jon (2000): Freakshow: First Person Media and Factual Television. London: Pluto Press.

Eco, Umberto (1997): Innovation and Repetition: Between Modern and Postmodern Aesthetics. In: Capozzi, Rocco (ed..): Reading Eco: An Anthology. Bloomington: Indiana UP, pp. 14-33.

Ellerbrock, Dagmar/Koch, Lars/Müller-Mall, Sabine et al. (2017): Invektivität - Perspektiven eines neuen Forschungsprogramms in den Kultur- und Sozialwissenschaften. In: Kulturwissenschaftliche Zeitschrift 2/1, pp. 2-24.

Feuer, Jane. (1992): Genre Study and Television. In: Allen, Robert C. (ed.): Channels of Discourse, Reassembled: Television and Contemporary Criticism. Chapel Hill: U of North Carolina P, pp. 138-160.

Flynn, Caitlin/Mitchell, Christy (2014): 'It may be verifyit that thy wit is thin.': Interpreting Older Scots Flyting through Hip Hop Aesthetics. In: Oral Tradition 29/1, n.pg.

Fowler, Alastair (1982): Kinds of Literature: An Introduction to the Theory of Genres and Modes. Cambridge: Harvard UP.

Frye, Northrop (1957): Anatomy of Criticism: Four Essays. New Haven: Princeton UP.

Gillespie, Tarleton/Bockowski, Pablo J./Foot, Kirsten A. (eds.) (2014): Media Technologies: Essays on Communication, Materiality, and Society. Cambridge: MIT P.

Griffin, Dustin H. (1994): Satire: A Critical Reintroduction. Lexington: UP of Kentucky.

Hempfer, Klaus W. (1973): Gattungstheorie. München: Fink. Hendricks, Jacquelyn (2012): A Battle of 'Trechour Tung[s]': Gaelic, Middle Scots, and the Question of Ethnicity in Scottish Flyting. In: Fifteenth-Century Studies 37, pp. 71-96.

Huber, Patrick (1995): A Short History of 'Redneck': The Fashioning of a Southern White Masculine Identity. In: Southern Cultures 1/2, pp. 145-166.

Hutchby, Ian (2001): Technologies, Texts and Affordances. In: Sociology 35/2, pp. 441-456.
Jaussen, Paul (2018): Spectral Affordances of the Catalogue. In: Comparative Literature 70/2, pp. 160-175.

Kanzler, Katja (2019): (Meta-)Disparagement Humour: The Poetics and Politics of Mockery in the Sitcom Two Broke Girls. In: Hägi-Mead, Sara/Flubacher, Mi-Cha (eds.): Taboo and Transgression. Dresden: Theoretische Beiträge des Zentrums für Integrationsstudien, pp. 15-24.

Kanzler, Katja (2019): Veep, Invective Spectacle, and the Figure of the Comedic Antiheroine. In: Zeitschrift für Anglistik und Amerikanistik 67/2, pp. 147-162.

Kelleter, Frank/Jahn-Sudmann, Alexander (2012): Die Dynamik serieller Überbietung: Amerikanische Fernsehserien und das Konzept des Quality-TV. In: Kelleter, Frank (ed.): Populäre Serialitität: Narration Evolution - Distinktion. Bielefeld: Transkript, pp. 205-224.

Koblin, John (2019): Stephen Colbert Signs a New 'Late Show' Deal through 2023. In: The New York Times, 17 Oct. 2019: https://www.nytimes.com/2019/10/17/ business/media/stephen-colbert-late-show-cbs.html (last access: 18.11.2020).

Knight, Charles A. (2004): The Literature of Satire. Cambridge: Cambridge UP.

Lauter, Paul (1999): Reconfiguring Academic Disciplines: The Emergence of American Studies. In: American Studies 40/2, pp. 23-38.

Levine, Caroline (2015): Forms: Whole, Rhythm, Hierarchy, Network. New Haven: Princeton UP.

Magary, Drew. (2013): What the Duck? In: GQ, 18 December 2013: https://www.gq.com/story/duckdynasty-phil-robertson (last access: 18.11.2020).

Marshall, Kellie (2015). Rednecks: A Brief History. In: JSTOR Daily, 7 April 2015: https://daily.jstor.org/ redneck-a-brief-history/ (last access: 18.11.2020).

Norman, Donald (2002): The Design of Everyday Things. New York: Basic Books.

O'Sullivan, Shannon E.M. (2016): Playing 'Redneck': White Masculinity and Working-Class Performance on Duck Dynasty. In: Journal of Popular Culture 49/2, pp. 367-384.

Parks, Ward (1986): Flyting, Sounding, Debate: Three Verbal Contest Genres. In: Poetics Today $7 / 3$, pp. 439-458.

Phiddian, Robert (2013): Satire and the Limits of Literary Theories. In: Critical Quarterly 55/3, pp. 44-58.

Rawson, Claude (1994): Satire and Sentiment, 1660-1830: Stress Points in the English Augustan Tradition. Cambridge: Cambridge UP.

Tyler May, Elaine (2003): 'Family Values': The Uses and Abuses of American Family History. In: Revue Franchise d'Etudes Americaines 97, pp. 7-22.

Von Contzen, Eva (2017): Die Affordanzen der Liste. In: Zeitschrift für Literaturwissenschaft und Linguistik 47/3, pp. 317-326.

Wicks, Ulrich (1989): Picaresque Narrative, Picaresque Fictions: A Theory and Research Guide. Westport: Greenwood P. 